\title{
Different Rule-based Control Schemes for a Series Hydraulic Hybrid Vehicle
}

\author{
Tri-Vien $\mathrm{Vu}$ \\ Correspondence: Tri-Vien Vu, Faculty of Electrical and Electronics Engineering, Ton Duc Thang University, No. 19 \\ Nguyen Huu Tho Street, Tan Phong Ward, District 7, Ho Chi Minh City, Vietnam.
}

Received: June 7, 2016 Accepted: June 21, 2016 Online Published: July 25, 2016

doi:10.11114/set.v3i1.1659

URL: http://dx.doi.org/10.11114/set.v3i1.1659

\begin{abstract}
In a hybrid hydraulic vehicle, the hydraulic accumulator is used as the secondary power source in addition to the engine to propel the vehicle. Since the accumulator is a passive power source, it will be only used to compensate the difference between the power demand and the power delivery by the engine. Obviously, the main energy consumption is the engine. Hence a straightforward strategy to improve the fuel economy is to reduce the engine operating period. In contrast, because of the low energy density characteristic, the accumulator can only afford the required power in a short period. As a consequence, the hydraulic hybrid vehicle has been concluded only suitable for start-stop-and-go driving pattern. This paper present different rule-based control schemes for a 3.5- ton series hydraulic hybrid truck. The simulation results indicate that by applying suitable control scheme, the proposed series hydraulic hybrid system offers improvements of fuel economy for both urban and highway driving condition. The improvement is of $42.67 \%$ and $36.56 \%$ for urban and highway driving conditions, respectively in comparison with the corresponding conventional vehicle.
\end{abstract}

Keywords: rule-based control scheme, energy management, series hydraulic hybrid, modeling

\section{Introduction}

In hybrid vehicles, there are two or more different power sources available. The main function of control system is to coordinate these sources to satisfy the power demand of the driveline with minimum fuel consumption in the most convenient way. In general, control scheme of the hybrid propulsion systems can be classified into rule-based control strategies and optimization-based control strategies. Typical control strategies for hydraulic hybrid vehicle was reviewed and evaluated by Karbaschian et.al. (2014).

Because of its simplicity on design and implementation, ruled-based control scheme is generally the first choice to study a new configuration of the hybrid vehicle. Most papers regarding rule-based control strategy for hydraulic hybrid vehicle used the State-Of-Charge of the accumulator as the sole state variable for engine power determination (Wu, B., et.al, 2004, Filipi, Z., 2010; and Kim, Y., 2007). The main goal is to move the ICE operating point closer to optimal region of fuel economy, efficiency, and emissions. The rules are designed with the aid of ICE operating maps, power flows within the powertrain, and driving experience. However, how to regulate the engine to its reference power was not presented in these studies.

Tao et. al (2013) developed a threshold-based energy management strategy based on the thresholds of the engine efficient operation and SoC. In this control scheme, the engine efficiency map is divided into three areas by two constant power lines. The power demand will be compared with the two power thresholds and the suitable decision will be made. The two power thresholds can be optimized by using dynamic programming (DP) technique (Kum et. al. 2011). Moreover, the rule-based control scheme can also be optimized by using DP (Filipi et.al, 2004). The optimal variables are gear-shifting and logic-base switching rule.

To realize the control scheme, Kim (2008) used a PI controller to control the engine speed. The PI controller uses vehicle velocity error as the input. Engine torque is controlled by adjusting the control signal of the fuel rack. Control of vehicle velocity is not discussed explicitly in this study. Engine speed and vehicle velocity are controlled by individual PID controllers (Shan, M., 2009). Controller parameter tuning, input-output interaction and physical constraint are obstacles to this control approach.

Focusing on developing a rule-based control scheme for a 3.5 ton SHHV truck class, in this work, different approach to estimate the demand power of the engine for a giving command from the driver will be studied. To evaluate the 
effectiveness of the proposed control schemes, Japan 1015 and highway fuel economy test (HWFET) driving cycles are used as the velocity trajectory references. The system fuel economy improvement is also investigated. The simulation results show that when the vehicle operates under urban driving condition, the third control scheme can be selected because it offers a highest fuel economy. However, if the vehicle works on highway condition, the fifth control scheme helps the system achieves a better improvement.

\section{System Description and Modeling}

\subsection{System Description}

A schematic of the series hydraulic hybrid powertrain configuration for a rear-wheel-drive light-duty truck is presented in Figure 1. A variable displacement hydraulic pump is connected to an engine to convert mechanical power into hydraulic power. The power is stored in the accumulator or converted back to mechanical power by a variable displacement pump/motor. The pump/motor is a reversible energy conversion component. When working as a motor, it converts the hydraulic power into mechanical power to propel the wheels. When the brake pedal is depressed, the pump/motor works as a pump. The momentum of the vehicle is used to pressurize fluid from the reservoir and stores it in the accumulator. In this manner, the mechanical brake power is converted into hydraulic power. The braking energy is captured and stored in the accumulator in the form of hydraulic high pressure. The low-pressure reservoir provides fluid for the hydraulic system.

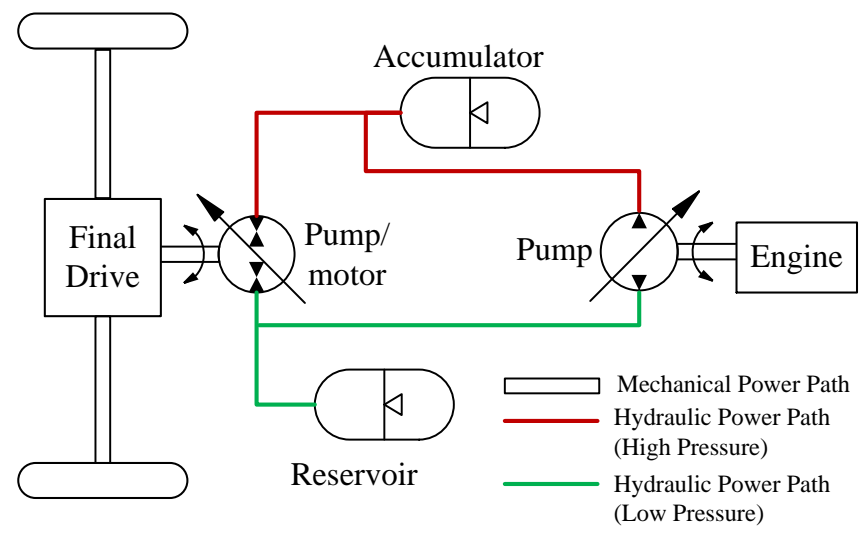

Figure 1. Schematic and Control Signal Paths of SHHV

\subsection{Mathematical Model}

Seleting the engine angular speed, accumulator pressure and vehicle velocity as the state variables, the dynamics of the SHHV system can be briefly expressed by following equation.

$$
\begin{gathered}
\dot{\omega}_{e}=\frac{1}{J_{e p}}\left(u_{3}\left(k_{1}+k_{2} \omega_{e}+k_{3} \omega_{e}^{2}\right)-u_{1} D_{1} p\right) \\
\dot{p}=\frac{1.4 \beta}{\left(1.4 V_{\mathrm{h}}+\beta V_{a} p_{\mathrm{pr}}^{1 / 1.4} p_{\mathrm{h}}^{-2.4 / 1.4}\right)}\left(u_{1} D_{1} \omega_{\mathrm{e}}-u_{2} D_{2} v \frac{i_{\mathrm{df}}}{r_{\mathrm{w}}}\right) \\
\dot{v}=\frac{1}{m}\left(u_{2} D_{2} p \frac{i_{\mathrm{df}}}{r_{\mathrm{w}}}-\frac{1}{2} \rho C_{\mathrm{d}} A v^{2}-m g f_{\mathrm{r}} \cos (\theta)-m g \sin (\theta)\right)
\end{gathered}
$$

In the above equations, the first one represents the engine dynamic, the second represents the thermodynamic of the accumulator, and the third expresses the dynamic of the wheels. The model can also be represented in the form:

$$
\begin{aligned}
\dot{\mathbf{x}} & =\mathbf{f}(\mathbf{x}, \mathbf{u}, t) \\
\mathbf{y} & =\mathbf{g}(\mathbf{x}, \mathbf{u}, t)
\end{aligned}
$$

where the state vector $\mathbf{x}=\left[\omega_{\mathrm{e}} p v\right]^{T}$ consists of the engine speed $-{ }_{\mathrm{e}}$, the accumulator pressure $-\mathrm{p}$, and the vehicle speed - v. The controlled output vector $\mathbf{y}_{\mathrm{r}}=\left[\begin{array}{llll}\omega_{\mathrm{e}} & T_{\mathrm{e}} & p & v\end{array}\right]^{T}$. The input vector $\mathbf{u}=\left[\begin{array}{lll}u_{1} & u_{2} & u_{3}\end{array}\right]^{T}$ includes the normalized displacement factor of the pump $-\mathrm{u}_{1}$, the pump/motor $-\mathrm{u}_{2}$, and the normalized amount of fuel mass 
injected into the combustion chamber $-\mathrm{u}_{3}$. Details of the mathematical model can be found in our previous work (Vu et. al., 2014).

\section{Control System Development}

As has been mentioned, in a hybrid vehicle the control system is used to ensure that not only the dynamic constrained but also the power demand is satisfied in the most efficient manner. For this purpose, the control system is decomposed into two control loops as shown in Figure 2. The inner loop is used to guarantee the dynamic constraints. The outer loop, so called the supervisory controller, coordinates the two power sources to satisfy the power demand.

To guarantee the dynamic constraints of the system, the inner loop controller uses three individual PID controllers. The first PID uses engine speed error as the input. The output of this controller is the control signal to adjust the total amount of the injected fuel mass of the engine, $u_{3}$. The function of the second PID is to adjust the engine output torque by controlling the displacement of the pump. The desired vehicle velocity is guaranteed by the third PID controller which adjust the displacement of the pump/motor to compensate the vehicle velocity error.

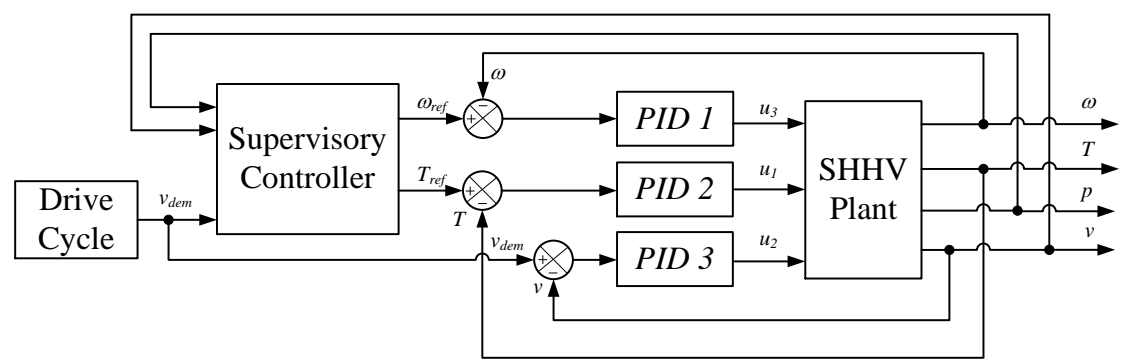

Figure 2. Hierarchical control system of the SHHV

Since the accumulator is a passive power source, it will be only used to compensate the difference between the power demand and the power delivery by the engine. In addition, in the hydraulic hybrid vehicle, the main energy consumption is the engine. Hence it is obvious that to reduce the fuel consumption, the engine operating period should be reduced. However, because of the low energy density characteristic, the accumulator can only afford the required power in a short period, after that the engine must be involved.

Focusing on the development of the rule-based control strategies, this work presents several approaches to define the "rule" for determining the engine torque and engine speed for a given vehicle speed demand. In the first approach, only vehicle speed is used as the feedback variable. The speed error is the input for the PID controller and the output of the PID is the power demand as shown in Figure 3. Since the required power from the wheel is not related to the power delivered by the engine directly, the accumulator will be used to compensate the difference power. However, due to its low energy density characteristic, the accumulator is easy going into the depletion or full-charged stage. When the accumulator is full-charged the extra power will be wasted and when it is depleted the system will be fail.

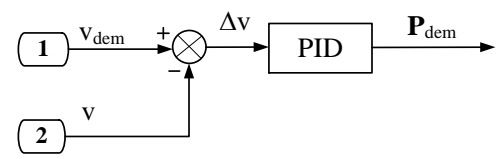

Figure 3. Schematic of the First Control Scheme

To overcome the drawback of the first approach, in the second approach, the pressure of the accumulator is used as a safe-ward variable. The engine will be turned on if the pressure of the accumulator is within $\left[p_{i n}, p_{\max }\right]$. If the pressure exceeds the high threshold value, $p_{\max }$, the engine will be turned off. The schematic of the second control scheme is shown in Figure 4.

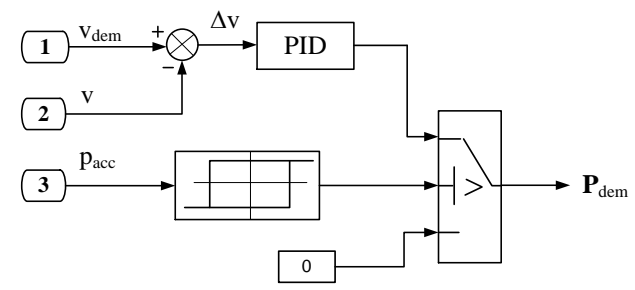

Figure 4. Schematic of the Second Control Scheme 
One of the distinguish feature of the SHHV is that the engine is decoupled from the wheels. From the engine map, it can be seen that each engine has a sweet-spot area, at which the engine brake specific fuel consumption (bsfc) is smallest. It means that the engine consumes a smallest amount of fuel to deliver a specific power. Using this feature, the third control scheme is straightforward; the engine is turned on or off due to the current pressure of the accumulator. When the engine is turned on, it will operate at its highest efficiency region. The control algorithm is shown in Figure $\mathbf{5}$.

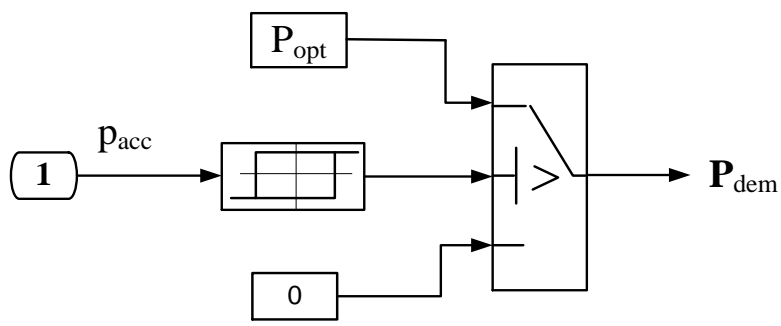

Figure 5. Schematic of Third Control Scheme

Another approach is based on the assumption that the engine is used to regulate the pressure of the accumulator at a particular value regardless the demand from the vehicle driver. In this manner, the engine power demand is estimated based on the different between the preset and the current value of the accumulator pressure. Figure 6 presents a schematic of the fourth control strategy.

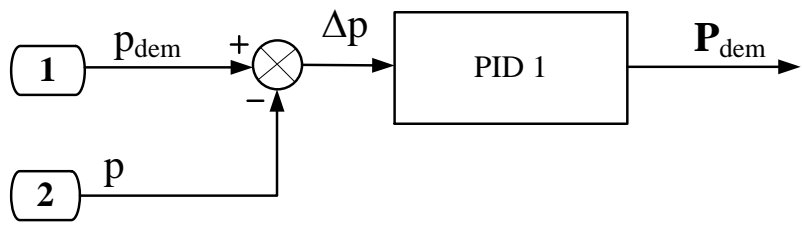

Figure 6. Schematic of the Fourth Control Scheme

The idea of considering the pressure as a function of velocity demand originates from the fact that when the demand velocity is low, the engine can charge the pressure to a high value which allows to supply a higher power in the future. Besides, a higher velocity demand would require a lower pressure accumulator in order to reserve sufficient accumulator volume to enable the storage of braking energy. As a consequence, the reference value of the accumulator is calculated to ensure that the amount of the energy stored in the accumulator according to the variation of the pressure from the reference value to the maximum one will equal to the vehicle kinetic energy at the demand speed. Hence, the reference value of pressure in the accumulator is obtained as follows:

$$
p_{\text {ref }}=\left(p_{\max }^{2 / 7}-\frac{1}{5} \frac{m v_{\mathrm{dem}}^{2}}{V_{\mathrm{a}} p_{\mathrm{pr}}^{5 / 7}}\right)^{7 / 2}
$$

Where $p_{\max }$ is the rated pressure of the accumulator, $\mathrm{m}$ is the vehicle total mass, $\mathrm{v}_{\mathrm{dem}}$ is the demand vehicle speed, $\mathrm{V}_{\mathrm{a}}$ and $\mathrm{p}_{\mathrm{pr}}$ are the capacitor and the pre-charged pressure of the accumulator, respectively.

The engine power is used to compensate the difference between the current value of the accumulator's pressure and its corresponding reference. The schematic of this control strategy is shown in Figure 7.

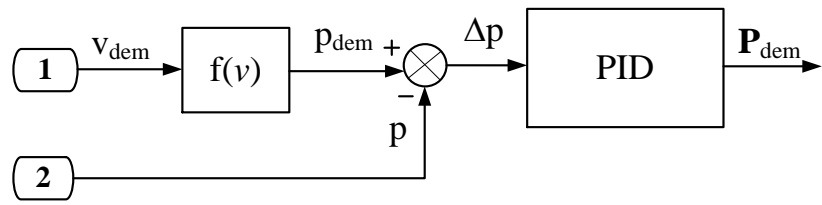

Figure 7. Schematic of the Fifth Control Scheme

The next step is to estimate the desired engine torque and engine speed for a given power demand. In a conventional vehicle, since there exists a mechanical coupling between the engine and the wheels, the engine torque and engine speed is related to the wheel toque and speed directly. In contrast, with the series HHV configuration, the engine is decoupled from the wheel, therefore it can be controlled to operate at any operating point in its torque-speed map theoretically.

A desired operating point of the engine is normally where the engine generating an output power with minimum fuel consumption. Therefore, it is necessary to find the optimum value of the engine torque and engine speed corresponding to a desired engine power demand. Based on the experimental data, the optimal speed of the engine for a desired power 
can be approximately estimated by a third order polynomial as given below.

$$
\omega_{\text {ref }}=k_{2}\left(P_{\mathrm{dem}}-k_{1}\right)^{3}+k_{3}\left(P_{\mathrm{dem}}-k_{1}\right)^{2}+k_{4} P_{\mathrm{dem}}+k_{5}
$$

where $k_{1}=37.75, k_{2}=0.0311, k_{3}=0.044, k_{4}=52.83$, and $k_{5}=387.5$ are the experimental fitting coefficients. The corresponding engine torque is then determined by

$$
T_{r e f}=\frac{30}{\pi} \frac{1000 P_{d e m}}{\omega_{r e f}}
$$

\section{Simulation Results and Discussion}

To evaluate the effectiveness of the proposed control schemes, two typical driving Japan 1015 and HWFET, are selected as velocity reference trajectories. The engine power and accumulator pressure trajectories of the system when working with different control schemes under two driving cycles are shown in Figure 8 and Figure 9, respectively.
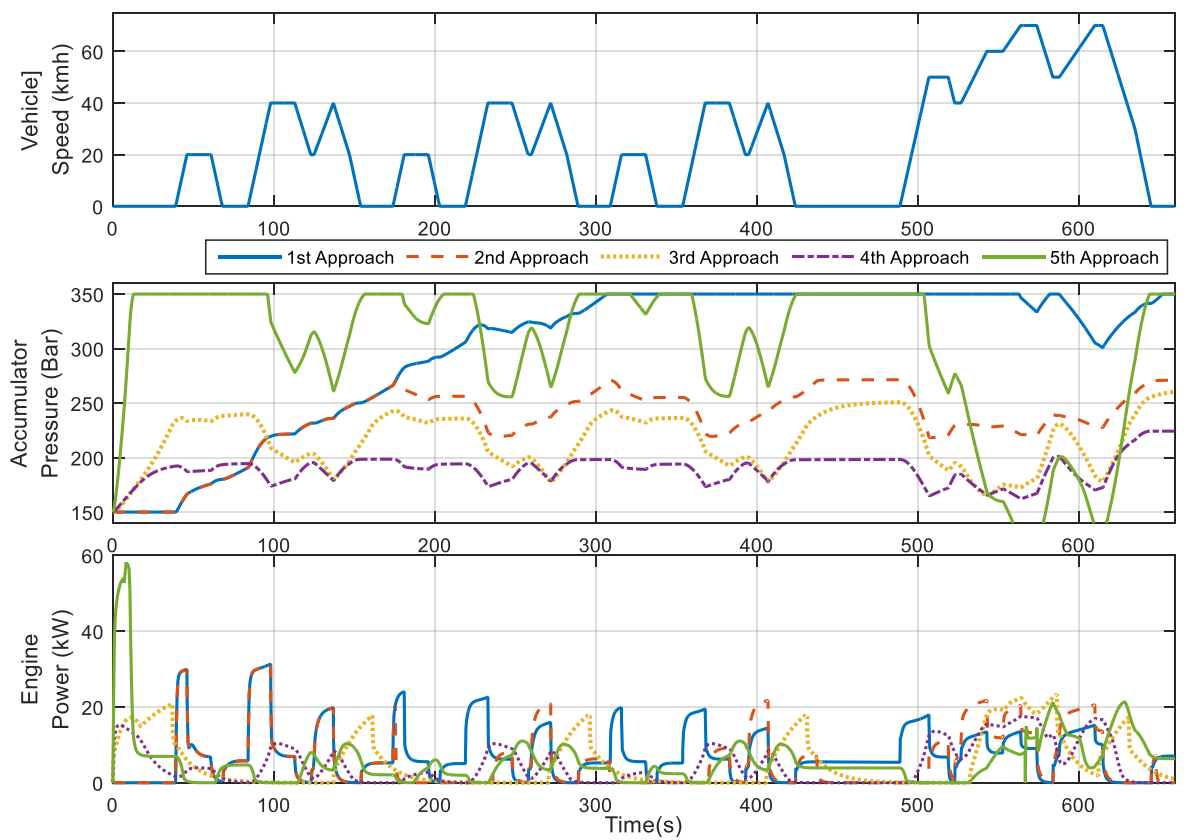

Figure 8. Engine Power and Accumulator Pressure under Japan 1015 Driving Cycle

It can be seen from Figure 8 that, with the first control scheme, the engine is active most of the time. During the period from second 300 second 560, the accumulator pressure reaches its maximum value but the engine power still deliver power even for a zero acceleration phases. It means that the extra fluid flows through the relief valve of the accumulator and the power delivery by the engine is wasted. The same phenomenon is taken place with the fifth control scheme.

With the second and the third control schemes, the accumulator pressure is maintained within a predefined range and the wasted energy is eliminated. By only used the accumulator as the feedback variable the third control scheme allows charging the accumulator during the stand still phases of the driving cycle while remaining the pressure within a predefined range. For a start-stop-and-go pattern, such as Japan 1015, this control scheme offers a best fuel economy improvement as will be shown later. 

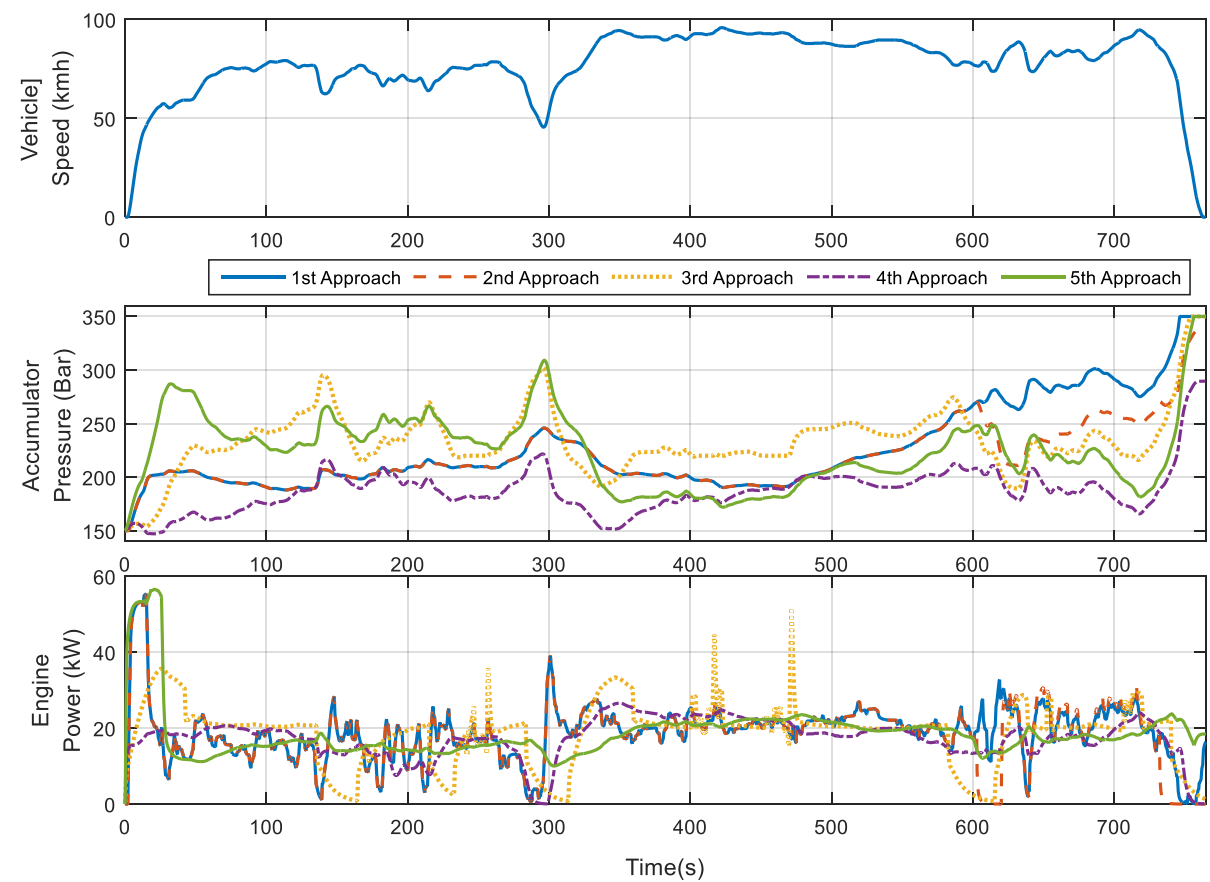

Figure 9. Engine Power and Accumulator Pressure under HWFET Driving Cycle

As can be seen from Figure 9, for a highway driving condition, if the control system only used the velocity error the calculate the reference output power of the engine, the first control scheme, the engine power will be varied due to the variation of the vehicle speed. As a consequence, the engine will be fluctuated with a high frequency. Similar situation has been taken place when applying the second and the third control schemes due to the low energy density characteristic of the accumulator. The fluctuation of the engine is eliminated significantly by applying the fourth control scheme. Further elimination is offered by the fifth one.

The fuel economy is defined as the average of the travel distance in kilometer for each liter of diesel fuel.

$$
F E=\frac{1000 m_{f}}{H_{f} S}
$$

where $\mathrm{H}_{\mathrm{f}}$ is the power density of the diesel fuel, $\mathrm{H}_{\mathrm{f}}=832[\mathrm{~g} / \mathrm{L}], \mathrm{m}_{\mathrm{f}}[\mathrm{g}]$ is the total mass of the consumed fuel, and $\mathrm{S}$ is the travel distance in $\mathrm{Km}$.

The fuel economy improvement of the system is defined as Eq.(9), in which $\mathrm{FE}_{S H H V}$ is the fuel economy of the series hydraulic hybrid and $\mathrm{FE}_{C O N V}$ is the fuel economy of the conventional vehicle.

$$
\mathrm{FEI}=\frac{F E_{S H H V}-F E_{C O N V}}{F E_{C O N V}} \times 100 \%
$$

The summary of fuel economy and the percent of fuel economy improvement of the SHHV system with the proposed control schemes under two typical driving conditions are given in Table 1. The conventional fuel economy here is obtained using the corresponding conventional vehicle model with the same parameters.

\begin{tabular}{|c|c|c|c|c|c|c|c|c|c|c|c|}
\hline & \multirow[b]{2}{*}{$\begin{array}{l}\text { Conv. } \\
\text { vehicle }\end{array}$} & \multicolumn{2}{|c|}{$1^{\text {st }}$ Approach } & \multicolumn{2}{|c|}{$2^{\text {nd }}$ Approach } & \multicolumn{2}{|c|}{$3^{\text {rd }}$ Approach } & \multicolumn{2}{|c|}{$4^{\text {th }}$ Approach } & \multicolumn{2}{|c|}{$5^{\text {th }}$ Approach } \\
\hline & & $\begin{array}{c}\mathrm{FE} \\
(\mathrm{km} / \mathrm{L})\end{array}$ & $\begin{array}{l}\text { FEI } \\
(\%) \\
\end{array}$ & $\begin{array}{c}\mathrm{FE} \\
(\mathrm{km} / \mathrm{L})\end{array}$ & $\begin{array}{l}\text { FEI } \\
(\%) \\
\end{array}$ & $\begin{array}{c}\mathrm{FE} \\
(\mathrm{km} / \mathrm{L}) \\
\end{array}$ & $\begin{array}{l}\text { FEI } \\
(\%) \\
\end{array}$ & $\begin{array}{c}\mathrm{FE} \\
(\mathrm{km} / \mathrm{L}) \\
\end{array}$ & $\begin{array}{l}\text { FEI } \\
(\%) \\
\end{array}$ & $\begin{array}{c}\mathrm{FE} \\
(\mathrm{km} / \mathrm{L}) \\
\end{array}$ & $\begin{array}{l}\text { FEI } \\
(\%) \\
\end{array}$ \\
\hline $\begin{array}{c}\text { Japan } \\
1015\end{array}$ & 10.08 & 10.96 & 8.03 & 14.2 & 29.01 & 17.58 & 42.67 & 15.44 & 34.72 & 13 & 22.46 \\
\hline HWFET & 11.57 & 13.38 & 13.53 & 13.54 & 14.55 & 13.86 & 16.52 & 15.61 & 25.88 & 18.24 & 36.56 \\
\hline
\end{tabular}

Table 1. Fuel economy of the SHHV with proposed control schemes

The result indicates that with the first control scheme, the fuel economy improvement is smallest. This result is predictable, because when the system only used vehicle speed as the feedback variable, the engine might deliver higher power than the demand. As a consequence, unnecessary energy conversion between the engine and the accumulator will be happening. In addition, the stored energy in the accumulator is not used, so even the braking energy is recovered, it will be wasted through the pressure relief valve. 
In the second control scheme, the unnecessary energy conversion is limited by using the low- and the high-threshold value of the accumulator pressure. In addition, by using the relay algorithm, the energy of the accumulator is used to propel the system. Hence, a better fuel economy improvement is achieved.

The system offers a further improvement when using the third control scheme due to the fact that the engine operates at its highest efficiency whenever it is turned on. For an urban driving cycle, such as Japan 1015, this control scheme offers a highest fuel economy improvement. The performance of the system with the third control scheme under Japan 1015 driving cycle is shown in Figure 10. However, when the vehicle operates under high-way condition, such as HWFET driving cycle, due to the low energy density of the accumulator, the engine will be fluctuated with high frequency. The long-term transient operating condition may cause the engine to consume more fuel as well as the pollutant emission.
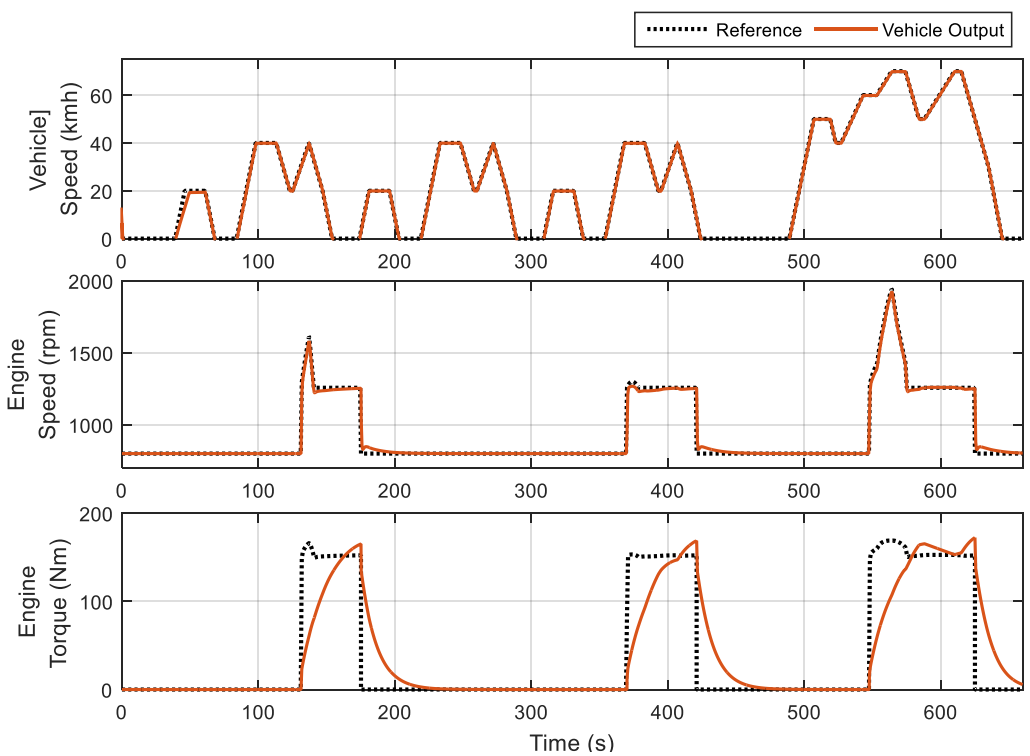

Figure 10. System Performance under Japan 1015 with the third Control Scheme

By maintaining the accumulator pressure at a certain level, the control system prevents unnecessary energy conversion from engine to accumulator. When the vehicle operates in the highway condition, this control scheme offers a better fuel economy. A further improvement can be achieved for the SHHV when working under highway condition by considering the reference value for the pressure of the accumulator as a function of the vehicle demand speed. In this manner, the accumulator volume is reserved for regenerative braking when the vehicle speed is high and sufficient power is ready for a high acceleration demand. This control scheme not only helps the system to recover larger amount of braking energy but also to have a better dynamic performance as shown in .
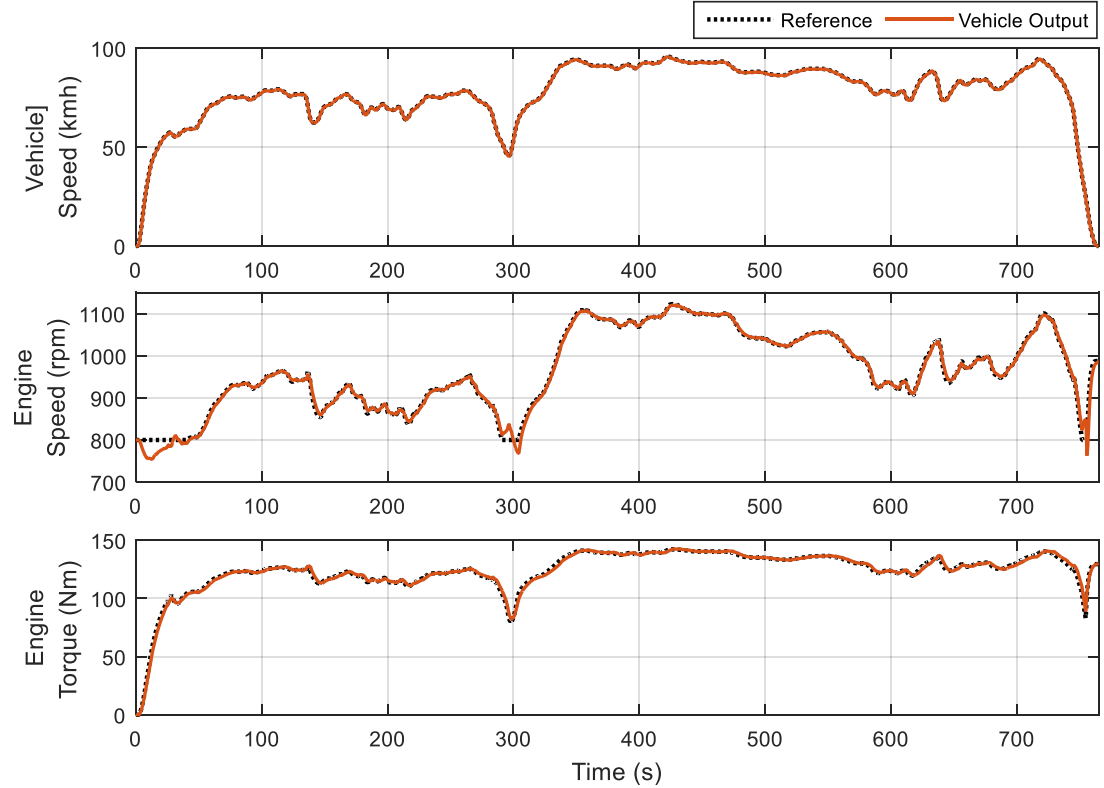

Figure 11. System Performance under HWFET with the Fifth Control Scheme 


\section{Conclusion}

With the aim of developing a real-time implementable control strategy for a series hydraulic hybrid vehicle system, this paper presents different approaches to estimate the power demand of the engine for a given driving condition based on the current pressure of the accumulator. The simulation results recommend that if the SHHV operates under start-stop-and-go pattern, such as Japan 1015, the engine will be turned on if the pressure of the accumulator is within a predefined range. Otherwise, the engine will be turned off. With this control scheme, the SHHV offers a fuel economy improvement of $42.37 \%$ in comparison to the conventional vehicle.

When the SHHV operates under highway driving condition, such as HWFET, the demand power of the engine is a determined from the error between the current value of the accumulator pressure and its reference value. The reference value of the accumulator pressure is defined as a function of the vehicle speed demand. With this control scheme, the accumulator volume is reserved for braking energy recovery and the accumulator power is prepared for high acceleration phases. Hence, a better fuel economy improvement will be achieved. In comparison with the fuel economy of the conventional vehicle, the SHHV offers an improvement of $36.56 \%$.

Currently, the control system proposed in this work is based on individual PID controllers, each of them have at least three control parameters need to be tuned. Hence, a controller parameter tuning technique should be considered in order to improvement the performance of the control system. In addition, since the SHHV is a multi-input-and-multi-output system, the interconnection between the inputs and outputs of the systems should also be taken into account to improve the system dynamic performance. In our future work, experimental test-rig will be focused to collect experimental data which will be used to validate the effectiveness of the proposed control schemes.

\section{References}

Ehsani, M., Gao, Y., Gay, S. E., \& Emadi, A. (2005). Modern Electric, Hybrid Electric, and Fuel Cell Vehicles; CRC Press: New York, NY, USA.

Feng, D., \& Huang, D. (2012). Modeling and Control of a Series Hydraulic Hybrid Vehicle. J. Comput. Inf. Syst., 8, $1805-1819$.

Filipi, Z., \& Kim, Y. J. (2010). Hydraulic Hybrid Propulsion for Heavy Vehicles: Combining the Simulation and Engine-In-the-Loop Techniques to Maximize the Fuel Economy and Emission Benefits. Oil Gas Sci. Technol., 65(1), 155-178. http://dx.doi.org/10.2516/ogst/2009024

Filipi, Z., Louca, L., Daran, B., Lin, C. C., Yildir, U., Wu, B., Kokkolaras, M., Assanis, D., Peng, H., \& Papalambros, P. (2004). Combined optimisation of design and power management of the hydraulic hybrid propulsion system for the 6X6 medium truck. Int. J. Heavy Veh. Syst., 11, 372-402. http://dx.doi.org/10.1504/IJHVS.2004.005458

Karbaschian, M. A., \& Söffker, D. (2014). Review and Comparison of Power Management Approaches for Hybrid Vehicles with Focus on Hydraulic Drives. Energies, 7, 3512-3536. http://dx.doi.org/10.3390/en7063512

Kim, Y. A. (2008). Integrated Modeling and Hardware-in-the-Loop Study for Systematic Evaluation of Hydraulic Hybrid Propulsion Options. PhD. Dissertation, University of Michigan, MI, USA, 2008.

Kim, Y., \& Filipi, Z. (2007). Series Hydraulic Hybrid Propulsion for a Light Truck-Optimizing the Thermostatic Power Management. SAE Trans. J. Engines, 116, 1597-1609. http://dx.doi.org/10.4271/2007-24-0080

Kum, D., Peng, H., \& Bucknor, N. K. (2011). Supervisory Control of Parallel Hybrid Electric Vehicles or Fuel and Emission Reduction. J. Dyn. Syst. Meas. Control, 133, 102-112. http://dx.doi.org/10.1115/1.4002708

Shan, M. (2009). Modeling and Control Strategy for Series Hydraulic Hybrid Vehicles. PhD. Dissertation, Toledo Univ., OH, USA, 2009.

Tao, L., Jincheng, Z., Shuwen, W., \& Fangde, G. (2013). Logic Threshold Based Energy Control Strategy for Parallel Hydraulic Hybrid Vehicles. Res. J. Appl. Sci. Eng. Technol., 6, 2339-2344.

Wu, B., Lin, C. C., Filipi, Z., Peng H., \& Assanis, D. (2004). Optimal Power Management for a Hydraulic Hybrid Delivery Truck. J. Vehicle Syst. Dyn., 42(1-2), 23-40. http://dx.doi.org/10.1080/00423110412331291562

\section{(cc) $\mathrm{BY}$}

This work is licensed under a Creative Commons Attribution 3.0 License. 